\title{
Development of a zoning-based environmental-ecological coupled model for lakes: a case study of Baiyangdian Lake in northern China
}

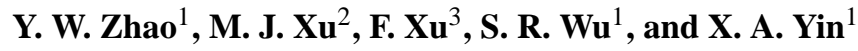 \\ ${ }^{1}$ State Key Laboratory of Water Environment Simulation, School of Environment, Beijing Normal University, \\ Beijing, 100875, China \\ ${ }^{2}$ Nanjing Institute of Environmental Sciences, Ministry of Environmental Protection, Nanjing, 210042, China \\ ${ }^{3}$ Beijing Municipal Research Institute of Environmental Protection, Beijing, 100037, China
}

Correspondence to: X. A. Yin (yinxinan@bnu.edu.cn)

Received: 10 December 2013 - Published in Hydrol. Earth Syst. Sci. Discuss.: 10 February 2014

Revised: - Accepted: 23 April 2014 - Published: 10 June 2014

\begin{abstract}
Environmental/ecological models are widely used for lake management as they provide a means to understand physical, chemical, and biological processes in highly complex ecosystems. Most research has focused on the development of environmental (water quality) and ecological models, separately. Limited studies were developed to couple the two models, and in these limited coupled models, a lake was regarded as a whole for analysis (i.e. considering the lake to be one well-mixed box), which is appropriate for small-scale lakes but is not sufficient to capture spatial variations within middle-scale or large-scale lakes. In response to this problem, this paper seeks to establish a zoning-based environmental-ecological coupled model for a lake. Hierarchical cluster analysis was adopted to determine the number of zones in a given lake based on hydrological, water quality, and ecological data analysis. The MIKE 21 model was used to construct 2-D hydrodynamics and water quality simulations. STELLA software was used to create a lake ecological model that can simulate the spatial variations of ecological condition based on flow field distribution results generated by MIKE 21. Baiyangdian Lake, the largest freshwater lake in northern China, was adopted as the study case. The results showed that the new model is promising for predicting spatial variations of ecological conditions in response to changes in lake water quantity and quality, and could be useful for lake management.
\end{abstract}

\section{Introduction}

Lakes are important freshwater ecosystems. They offer many irreplaceable ecological and social services, such as supporting biodiversity, regulating the water cycle, supplying water resources, and maintaining the regional ecological balance (Rubec and Hanson, 2009; Cai et al., 2011). In recent years, complex external disturbances have caused severe water quantity and quality problems in lakes (Kingsford, 2011). For example, flow regulation by upstream dams or reservoirs has resulted in decreasing water levels and shrinking water areas. Increasing pollution loads from agriculture and industry has aggravated lake eutrophication. To alleviate degradation and protect lake ecosystems, scientific management practices are urgently required.

Determining the relationships between water quality, aquatic ecology, and management tools for a lake should be a central task in establishing scientific lake management practices (Gal et al., 2009). In general, there are two approaches to establish relationships: statistical analysis of existing long-term databases, or modelling interactions. In reality, only a limited number of sufficiently long-term and detailed databases exist. In contrast to this, models allow simulation of an unlimited range of variables. Water environmental models are widely applied in lake management, as they provide a means to study and understand physical, biological, and chemical processes in highly complex ecosystems. The use of models in planning, designing, and testing management strategies has become increasingly common since the 1980s. Models allow us to explain water environmental 


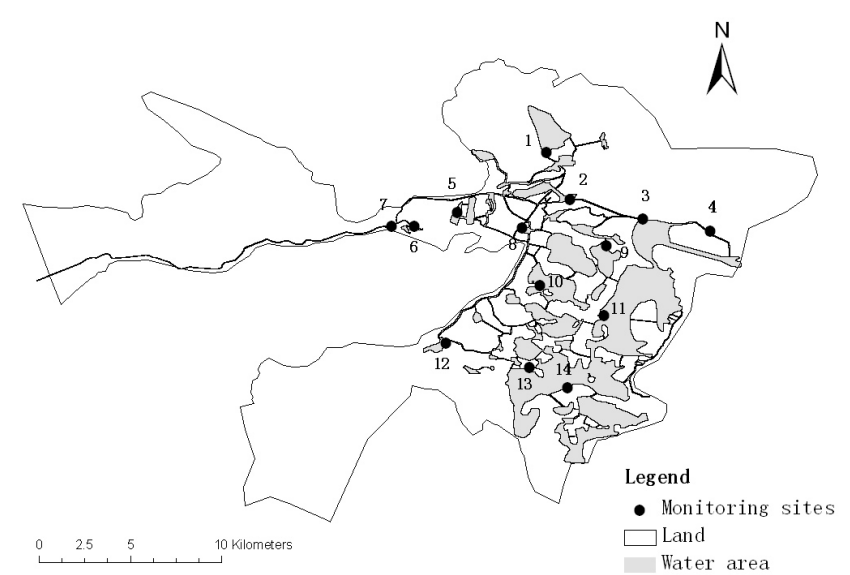

Figure 1. Distribution of the monitoring sites in Baiyangdian Lake.

problems and enhance understanding of lake ecology (Martins et al., 2008; Missaghi and Hondzo, 2010; He et al., 2011; Ciric et al., 2012).

Most lake models have focused on a single water quality or aquatic ecological process (Jørgensen, 2010; Miller et al., 2013). In fact, water quality and aquatic ecology interplay with each other, and it is essential to take both factors into consideration when constructing water environmental models. Recently, some scholars have attempted to construct integrated models: Muhammetoğlu and Soyupak (2000) proposed a dynamic 3-D water quality model for macrophytedominated shallow lakes. Their model is capable of simulating macrophytes and their interactions with water quality constituents such as dissolved oxygen (DO), organic nitrogen, ammonia, nitrate, organic phosphorus, orthophosphate, BOD, phytoplankton, and the sediment layer. Martins et al. (2008) developed a horizontal average model for prospective scenarios to reduce the risk of environmental degradation in Lake Sete Cidades. This model described thermal stratification, nutrient cycling, DO, and phytoplankton in the water column and adjacent sediment layer. Gal et al. (2009) applied the DYRESM-CAEDYM lake ecosystem model to estimate the impact of potential changes in nutrient loading on the Lake Kinneret ecosystem. The DYRESM hydrodynamics model is a 1-D model that simulates vertical stratification dynamics.

Most ecological models in existing integrated models regard the lake as a whole for analysis, i.e. considering the lake as one well-mixed box (Wang and Mitsch, 2000; Jørgensen, 2010; Xu et al., 2013). Such delineation is appropriate for small-scale shallow lakes, but is not sufficient to capture large spatial variations in hydrodynamics and constituent transport between different areas where the characteristics of soil, topography, water temperature, available nutrients, and vegetation show spatial heterogeneity within middle-scale or large-scale lakes. The well-mixed box model might contain a large margin of error (Wang et al., 2012). It is essential to

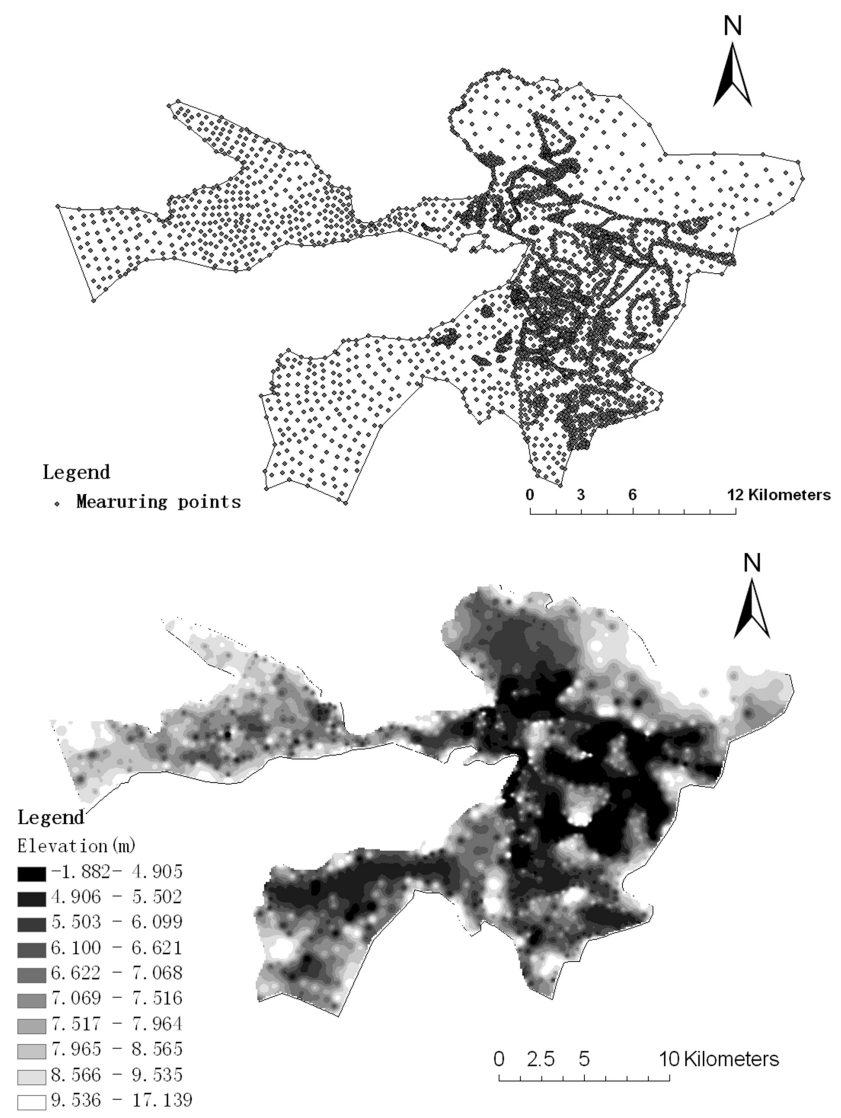

Figure 2. (a) Measuring point distributions; (b) terrain map of Baiyangdian Lake.

construct a lake ecological model that can simulate ecological change considering spatial variations.

This paper presents an integrated model system that can simulate and predict changes in hydrodynamics, water quality, and aquatic ecology. A typical meso-scale lake in China, Baiyangdian Lake, was taken as a case study. The aquatic ecological model was conceived to provide a compartmental model, which combines accuracy and computational efficiency, similar to other box ecological models, but with improved spatial resolution. First, a 2-D model, MIKE 21, was used to simulate the hydrodynamics and water quality of Baiyangdian Lake; second, an aquatic ecological model was constructed on the basis of aquatic ecological system characteristics in different water areas and flow field distributions generated by a MIKE 21 hydrodynamics model; third, a compartmental ecological model of four water area zones was constructed as an example using STELLA software and coupled to an integrated model by means of a hydrodynamic field modelled by MIKE 21, which can reflect the actual ecological conditions of Baiyangdian Lake in more detail. This integrated model system can provide a reference for water management and eutrophication prevention for Baiyangdian Lake. 


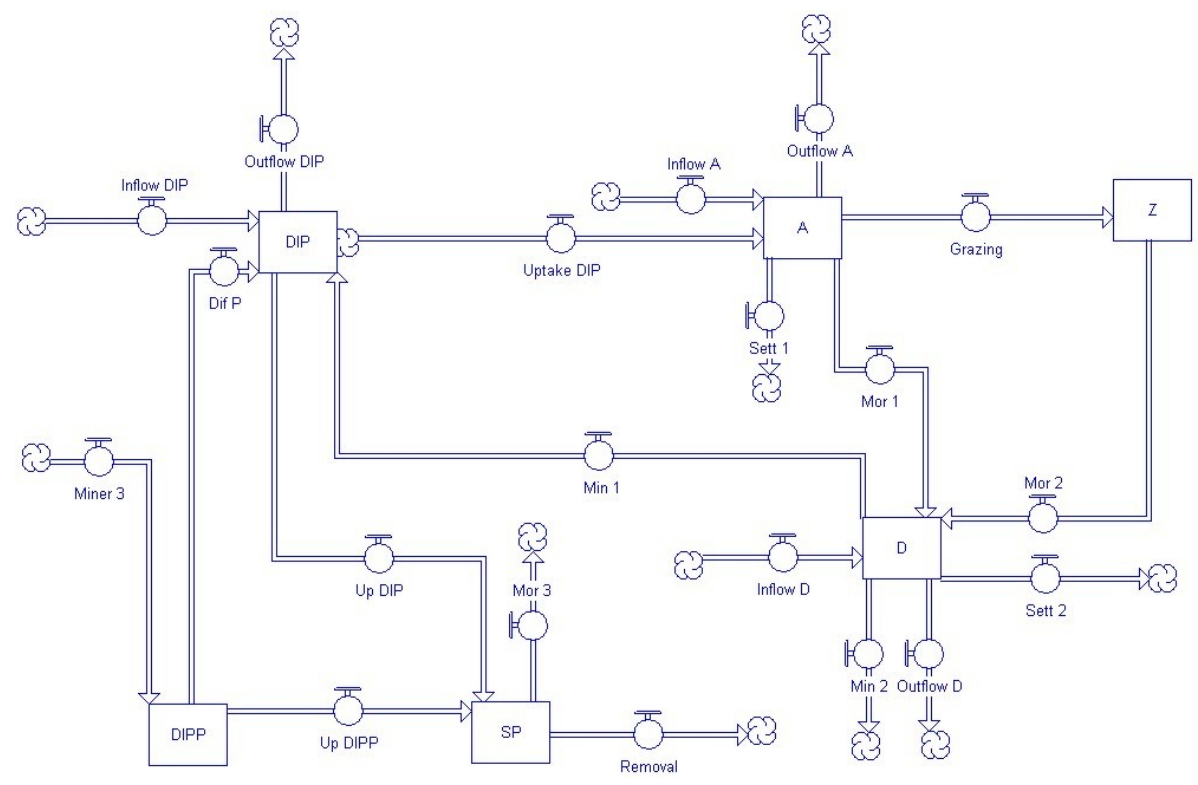

Figure 3. Conceptual diagram of each compartment model.

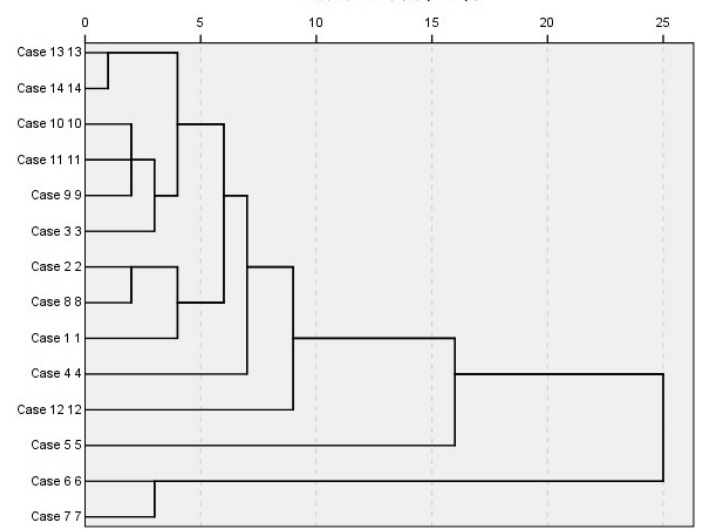

Figure 4. HCA results for 14 sampling sites.

\section{Methods}

\subsection{Study area and data sources}

Baiyangdian Lake $\left(115.75^{\circ} \mathrm{E}-116.12^{\circ} \mathrm{N}, 38.73-38.98^{\circ}\right)$ is located in the central North China Plain with an area of about $366 \mathrm{~km}^{2}$ when water level is $10 \mathrm{~m}$. It is a typical northern plant-dominated shallow wetland of about 143 individual lakes and $67 \mathrm{~km}^{2}$ of reed marshes. The terrain of Baiyangdian Lake is intricate. It is low in the east and high in the west, northwest, and south.

In recent years, as a result of the constant increase of industrial, agricultural, and domestic water use and impoundment of upstream water reservoirs, the average annual volume of water flowing into Baiyangdian decreased. Coupled with the impact of continuous dry years, Baiyangdian wet-
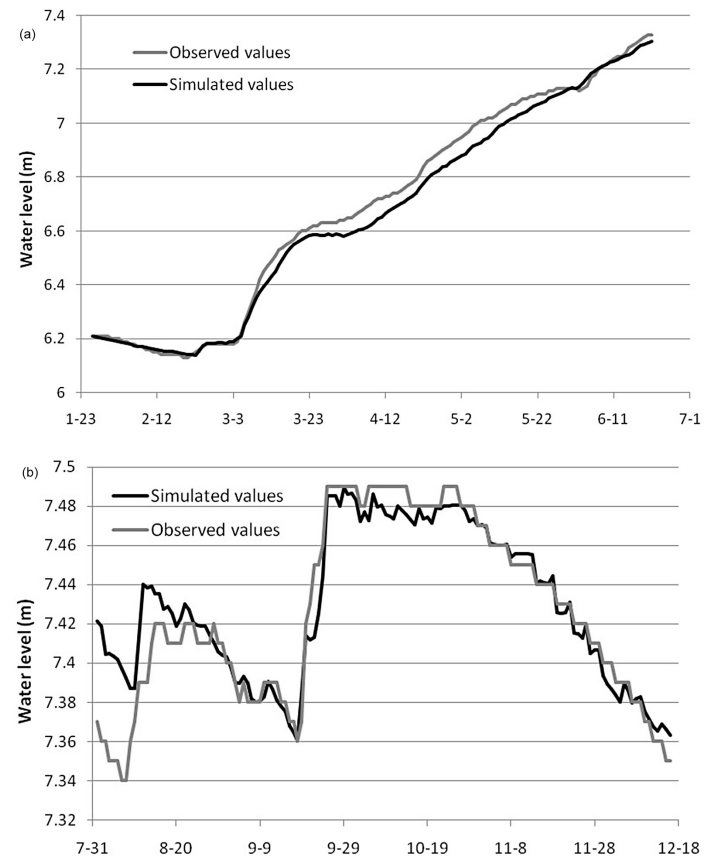

Figure 5. Calibration (a) and validation (b) results for water level.

land has suffered from severe drought multiple times since the 1980s, which has severely impacted the aquatic ecosystem. Meanwhile, as a result of population growth and economic development in the basin, Baiyangdian Lake has also suffered from intensive human disturbances. The Fu River is the only inflow river, and it carries a large quantity of pollutants, which results in serious eutrophication and biodiversity reduction. The unique environment and human landscape 
Table 1. Sampling site descriptions.

\begin{tabular}{|c|c|c|c|}
\hline No. & Sampling sites & Coordinate & Description \\
\hline 1 & Shaochedian & $38.940^{\circ} \mathrm{N}, 115.999^{\circ} \mathrm{E}$ & $\begin{array}{l}\text { A little aquaculture and large amount of submerged } \\
\text { plants }\end{array}$ \\
\hline 2 & Wangjiazhai & $38.917^{\circ} \mathrm{N}, 116.011^{\circ} \mathrm{E}$ & \multirow{2}{*}{ Aquaculture and dense distribution of villages } \\
\hline 3 & Yangzhuangzi & $38.908^{\circ} \mathrm{N}, 116.047^{\circ} \mathrm{E}$ & \\
\hline 4 & Zaolinzhuang & $38.902^{\circ} \mathrm{N}, 116.080^{\circ} \mathrm{E}$ & $\begin{array}{l}\text { A little human disturbances, more species and quantity } \\
\text { of macrophytes in clear water }\end{array}$ \\
\hline 5 & Yuanyangdao & $38.911^{\circ} \mathrm{N}, 115.955^{\circ} \mathrm{E}$ & Influenced a lot by tourism and Fu River \\
\hline 6 & Nanliuzhuang & $38.904^{\circ} \mathrm{N}, 115.934^{\circ} \mathrm{E}$ & \multirow{2}{*}{$\begin{array}{l}\text { Influenced a lot by wastewater inflow from Fu River } \\
\text { and a little aquaculture }\end{array}$} \\
\hline 7 & Entrance of Fu river & $38.904^{\circ} \mathrm{N}, 115.923^{\circ} \mathrm{E}$ & \\
\hline 8 & Zhainan & $38.903^{\circ} \mathrm{N}, 115.988^{\circ} \mathrm{E}$ & Aquaculture \\
\hline 9 & Guangdianzhangzhuang & $38.894^{\circ} \mathrm{N}, 116.029^{\circ} \mathrm{E}$ & Near to village \\
\hline 10 & Laowangdian & $38.875^{\circ} \mathrm{N}, 115.996^{\circ} \mathrm{E}$ & Aquaculture \\
\hline 11 & Quantou & $38.860^{\circ} \mathrm{N}, 116.028^{\circ} \mathrm{E}$ & \multirow{2}{*}{ Near to village and a lot of aquaculture } \\
\hline 12 & Duancun & $38.846^{\circ} \mathrm{N}, 115.950^{\circ} \mathrm{E}$ & \\
\hline 13 & Dongtianzhuang & $38.834^{\circ} \mathrm{N}, 115.991^{\circ} \mathrm{E}$ & Near to village and a little aquaculture \\
\hline 14 & Caiputai & $38.824^{\circ} \mathrm{N}, 116.010^{\circ} \mathrm{E}$ & A little aquaculture \\
\hline
\end{tabular}
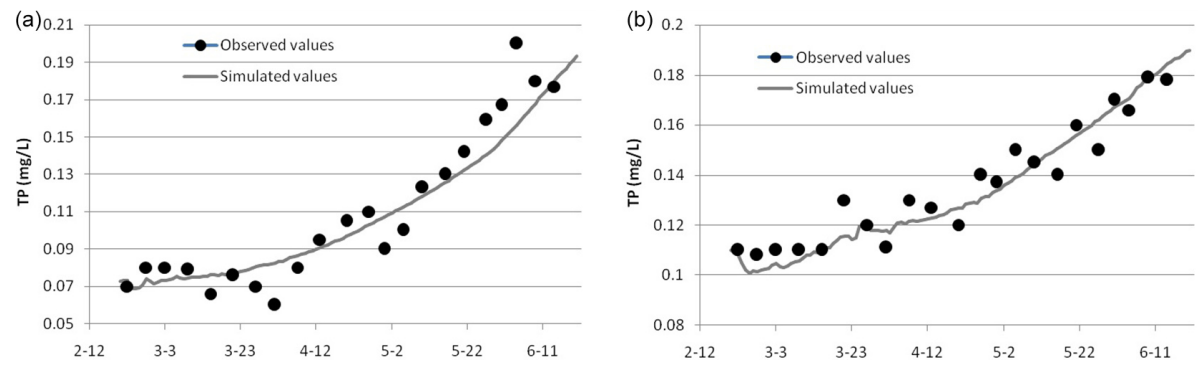

Figure 6. Calibration results for phosphate at sites 12 (a) and 11 (b).

of Baiyangdian Lake has gradually disappeared with severe negative effects on the health and sustainable development of the lake ecosystem.

Daily hydrological data for calibration and validation of the hydrodynamic model were obtained from the Municipal Water Conservancy Bureau. Daily meteorological data including wind velocity and precipitation taken as driving force factors were from China Meteorological Data Sharing Service System (http://cdc.cma.gov.cn). Water quality data for calibration and validation of the water quality model were obtained from the Municipal Environmental Protection Bureau for 14 water quality monitoring sites (Fig. 1 and Table 1) in Baiyangdian Lake from February 2008 to November 2008. Ecological data including phytoplankton biomass, zooplankton biomass, detritus concentration, and macrophyte biomass were obtained from bimonthly field sampling carried out from August 2009 to August 2010 to reflect seasonal changes in Baiyangdian Lake.

The Digital Orthophoto Map - Quickbird image (September 2007) covering an area of $366 \mathrm{~km}^{2}$ was interpreted by the software ENVI 4.4 and eCognition Developer 8.0 to identify water and land boundaries. Water depths in Baiyangdian Lake were obtained through high-density artificial field measurement. The spacing between the 3973 measuring points ranged from 50 to $300 \mathrm{~m}$. Lake bed elevation was the difference between water elevation and water depth at each measuring point. Land surface elevations around Baiyangdian Lake were extracted from Google Earth. Lakebed elevation data, land surface elevation data, water boundaries, and land boundaries were integrated using the geographic information system program ArcGIS (Fig. 2a). A topographic map of Baiyangdian Lake was generated by terrain interpolation (Fig. 2b).

Water area divisions of Baiyangdian Lake were made before the construction of the aquatic ecological model. Hierarchical cluster analysis (HCA) was adopted to objectively determine the number of zones in Baiyangdian Lake. The HCA was made on the basis of the analysis of hydrological, water quality, and ecological data of Baiyangdian Lake measured during field sampling at 14 sampling sites. A flow field 

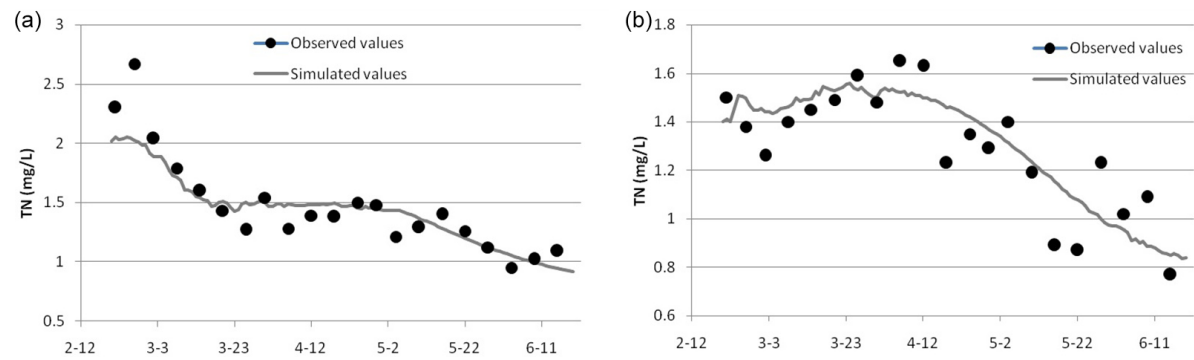

Figure 7. Calibration results for $\mathrm{TN}$ at sites 12 (a) and 11 (b).

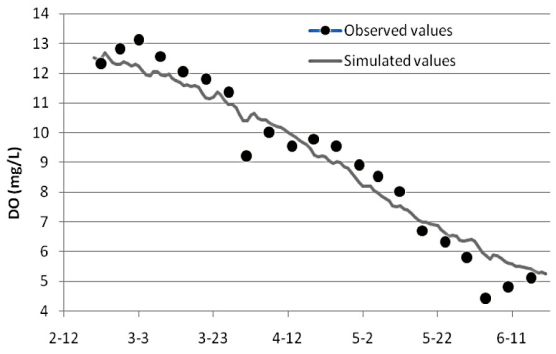

(a)

Figure 8. Calibration results for DO at sites 12 (a) and 11 (b).

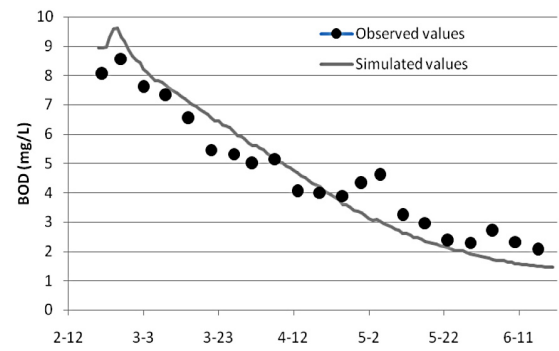

(a)

Figure 9. Calibration results for BOD at sites 12 (a) and 11 (b).

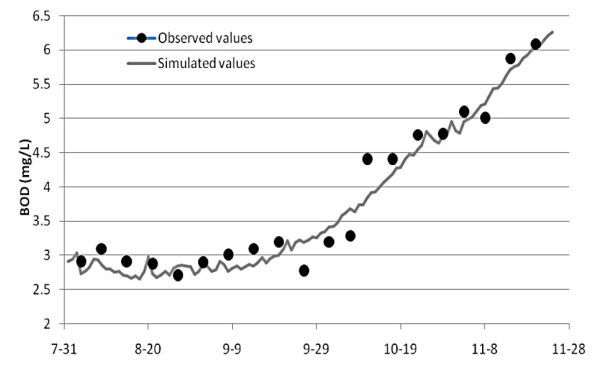

(a)

Figure 10. Validation results for BOD (a) and DO (b) at site 2.

distribution map generated by the MIKE 21 hydrodynamic model was used to test the rationality of the water area zoning results. Given the complexity of coupled ecological models, we considered that four or five zones would be sufficient.

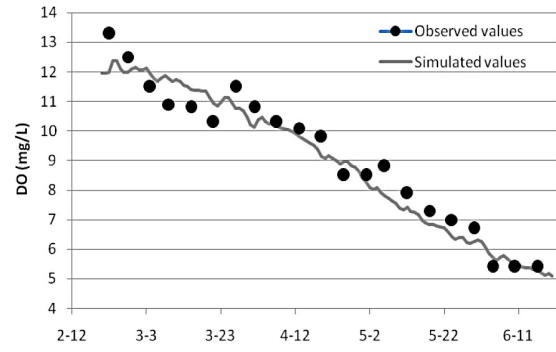

(b)

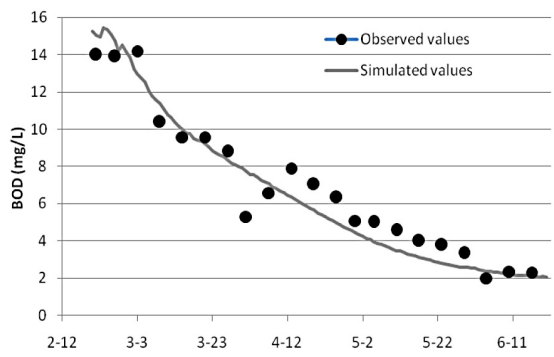

(b)

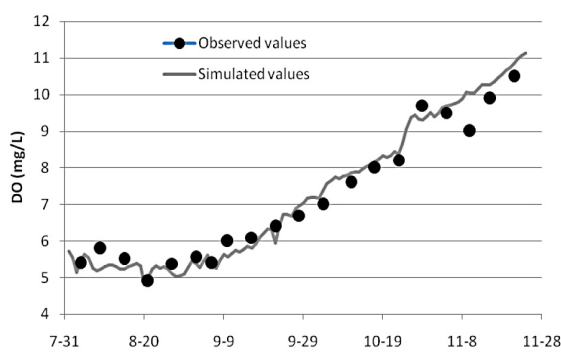

(b)

\subsection{Hydrodynamics and water quality model}

Baiyangdian Lake is a shallow lake with an average depth of around $2 \mathrm{~m}$ and with no obvious stratification, and thus a 2 $\mathrm{D}$ numerical model is suitable for simulating hydrodynamics 
Table 2. Conversion process for each state variable.

\begin{tabular}{lll}
\hline Symbol & Description & Unit \\
\hline Uptake DIP & Uptaking phosphorus rate by phytoplankton & $\mathrm{mg} \mathrm{L}^{-1}$ per day \\
Grazing & Grazing phytoplankton by zooplankton & $\mathrm{mg} \mathrm{L}^{-1}$ per day \\
Mor1 & Mortality of phytoplankton & $\mathrm{mg} \mathrm{L}^{-1}$ per day \\
Sett1 & Settling phytoplankton to the sediment & $\mathrm{mg} \mathrm{L}^{-1}$ per day \\
Inflow A & Inflow rate of phytoplankton & $\mathrm{mg} \mathrm{L}^{-1}$ per day \\
Outflow A & Outflow rate of phytoplankton & $\mathrm{mg} \mathrm{L}^{-1}$ per day \\
Mor 2 & Mortality of zooplankton & $\mathrm{mg} \mathrm{L}^{-1}$ per day \\
up P & Uptaking phosphorus rate from lake water phase by aquatic plants & $\mathrm{mg} \mathrm{L}^{-1}$ per day \\
up PP & Uptaking phosphorus rate from pure water phase by aquatic plants & $\mathrm{mg} \mathrm{L}^{-1}$ per day \\
Mor 3 & Mortality of aquatic plant & $\mathrm{g} \mathrm{m}^{-2}$ per day \\
Harvest & Reaping of aquatic plant & $\mathrm{g} \mathrm{m}^{-2}$ per day \\
Sett 2 & Settling detritus to the sediment & $\mathrm{mg} \mathrm{L}^{-1}$ per day \\
Min 1 & Mineralising to DIP & $\mathrm{mg} \mathrm{L}^{-1}$ per day \\
Min 2 & Mineralising to other materials & $\mathrm{mg} \mathrm{L}^{-1}$ per day \\
Inflow D & Inflow rate of detritus & $\mathrm{mg} \mathrm{L}^{-1}$ per day \\
Outflow D & Outflow rate of detritus & $\mathrm{mg} \mathrm{L}^{-1}$ per day \\
Inflow DIP & Inflow DIP rate & $\mathrm{mg} \mathrm{L}^{-1}$ per day \\
Dif P & Diffusion phosphorus to water phase from pore water & $\mathrm{mg} \mathrm{L}^{-1}$ per day \\
Outflow DIP & Outflow rate of DIP & $\mathrm{mg} \mathrm{L}^{-1}$ per day \\
Min 3 & Mineralised phosphorus rate from exchangeable P in sediment & $\mathrm{mg} \mathrm{L}^{-1}$ per day \\
\hline
\end{tabular}

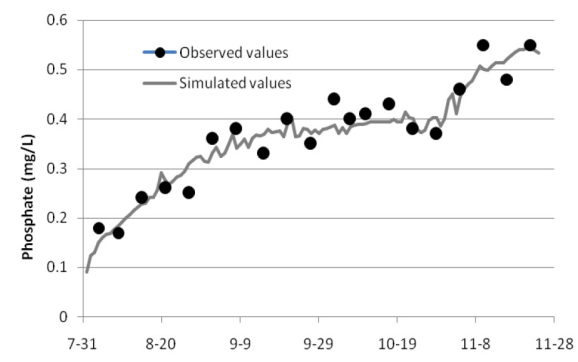

(a)

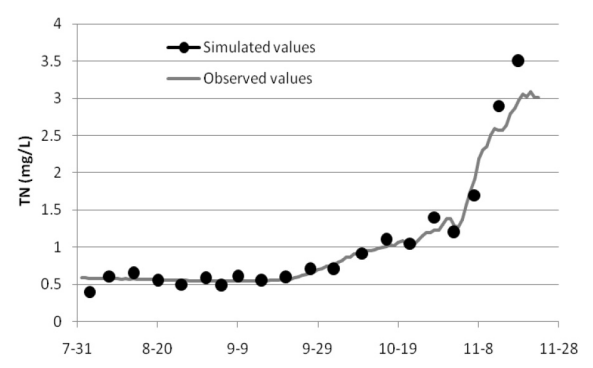

(b)

Figure 11. Validation results for phosphate (a) and TN (b) at site 2 .

and water quality. This research used the MIKE 21 model, which has been widely used in research (Cox, 2003) to simulate hydrodynamic indices including water level, water depth, flow velocity, and water quality indices including BOD, DO, phosphate, ammonia, nitrite, and nitrate.

Two model boundaries (Fu River and Dashuliuzhuang) were set. The Fu River is a perennial inflow, transferring water into Baiyangdian Lake. Dashuliuzhuang is the water inlet for the Yellow River-to-Baiyangdian Lake water diversion project, a project that has been carried out annually in recent years. Measured flow and water quality data of these two inlets were used as the boundary input conditions. The Zaolinzhuang release sluice is an outflow of Baiyangdian Lake; however, it is closed unless the water level is above $8.5 \mathrm{~m}$, so in our simulation the outflow volume was set to zero.
The model calibration was configured to run from 20 February 2008 to 20 June 2008 as in these months the watershed management department implemented the annual water transfer project to ensure a minimum water level $(6.5 \mathrm{~m})$, so there were significant differences in water levels and concentration of pollutants. Water-level and waterquality data for two typical monitoring points (site 12 and site 11) were used. 1 August 2008 to 30 November 2008 was selected as the model validation period. The model was run with a daily time step.

The MIKE 21 model includes a large number of userdefined parameters. Parameter values were sourced from recent experimental analysis on Baiyangdian Lake as well as relevant published literature and reports. For parameters with values that were not directly available, a series of model runs was performed to test goodness-of-fit values between 
Table 3. Sensitivity indices of parameters in the ecological model.

\begin{tabular}{|c|c|c|c|c|c|c|c|c|}
\hline $\begin{array}{l}\text { Parameter } \\
\text { (initial value) }\end{array}$ & Definition & S-DIP & S-D & S-DIPP & S-A & S-Z & S-AP & $\begin{array}{r}\text { All } \\
\text { variables }\end{array}$ \\
\hline CC (20) & Carrying capacity for zooplankton in a lake & 0.364 & -0.234 & 0.122 & -0.324 & 0.175 & 0.018 & 0.206 \\
\hline DIFFC $(0.1)$ & Diffusion rate & 0.051 & 0.094 & -0.213 & 0.107 & 0.072 & -0.005 & 0.090 \\
\hline $\operatorname{EXT}(0.2)$ & Extinction coefficient & 4.617 & -3.170 & 3.836 & -8.583 & -1.979 & -0.531 & 3.786 \\
\hline GAMAX (5) & Maximum growth rate for phytoplankton & 0.057 & 0.790 & 0.030 & 1.475 & 0.412 & 0.884 & 0.608 \\
\hline $\operatorname{GPMAX}(0.2)$ & Maximum growth rate for aquatic plant (Involving water body) & -1.215 & -2.280 & -0.584 & -3.125 & -2.086 & 0.280 & 1.595 \\
\hline GPOVMAX (0.05) & Maximum growth rate for aquatic plant (Involving pore water) & -1.019 & -2.227 & -2.243 & -2.615 & -1.760 & 0.126 & 1.665 \\
\hline $\operatorname{GZMAX}(0.1)$ & Maximum growth rate for zooplankton & 0.003 & 0.234 & 0.000 & 0.452 & 0.085 & 0.484 & 0.210 \\
\hline $\mathrm{KA}(0.5)$ & Michaelis constant for zooplankton from phytoplankton & -0.601 & 0.406 & -0.191 & 0.579 & -0.082 & -0.025 & 0.314 \\
\hline KI1 (300) & Michaelis constant for phytoplankton from sunlight & 0.300 & -0.231 & 0.102 & -0.339 & -0.160 & 0.014 & 0.191 \\
\hline KI2 (400) & Michaelis constant for aquatic plant from sunlight & -0.052 & 0.274 & 0.123 & 0.345 & 0.186 & -0.033 & 0.169 \\
\hline $\mathrm{KP}(0.03)$ & Michaelis constant for phytoplankton from DIP & 0.928 & -0.785 & 0.266 & -0.948 & -0.644 & 0.073 & 0.607 \\
\hline $\mathrm{KPP}(0.02)$ & Michaelis constant for aquatic plant from DIP & -0.613 & 0.473 & -0.104 & 0.571 & 0.272 & -0.108 & 0.357 \\
\hline Kpp1 (0.02) & Michaelis constant for aquatic plant from DIPP & 0.000 & 0.115 & 0.137 & 0.137 & 0.087 & -0.006 & 0.080 \\
\hline MA $(0.1)$ & Maximum mortality for phytoplankton & 0.027 & 0.401 & 0.015 & 1.214 & 0.169 & 0.199 & 0.338 \\
\hline $\operatorname{MAP}(0.01)$ & Maximum mortality for aquatic plant & -1.845 & 1.354 & -0.535 & 1.861 & 0.857 & -0.015 & 1.078 \\
\hline MZ $(0.05)$ & Maximum mortality for zooplankton & 0.005 & 0.534 & 0.005 & 0.725 & 0.135 & 0.367 & 0.295 \\
\hline NDC (0.3) & Mineralisation rate of organic detritus & -0.398 & 0.043 & -0.066 & 0.886 & 0.481 & -0.017 & 0.315 \\
\hline $\operatorname{SDR}(0.1)$ & Settling rate of organic detritus & -0.069 & -0.378 & -0.032 & -0.294 & -0.137 & 0.000 & 0.152 \\
\hline SDRA $(0.1)$ & Settling rate of phytoplankton & 0.006 & 0.114 & 0.006 & 0.285 & 0.017 & 0.142 & 0.095 \\
\hline thresh $(0.3)$ & Threshold for zooplankton grazing phytoplankton & -0.309 & 0.199 & -0.111 & 0.269 & -0.120 & -0.014 & 0.170 \\
\hline water ratio $(0.5)$ & Water ratio in sediment & 3.766 & -1.247 & 1.480 & -1.614 & -0.624 & -0.052 & 1.464 \\
\hline
\end{tabular}

The results in the table are based on STELLA 9.0 program by using parameters with $\pm 10 \%$ changes $I=\left[\left(y_{2}-y_{1}\right) / y_{0}\right] /\left[2 \Delta x / x_{0}\right]$.

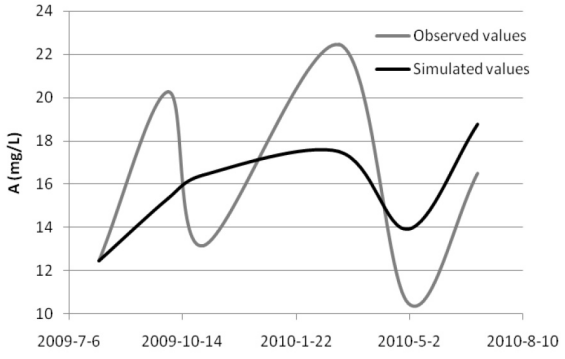

(a)

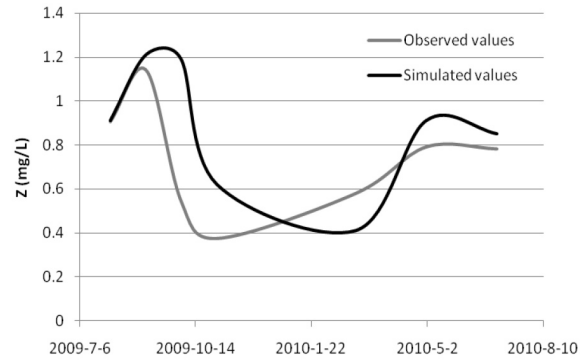

(b)

Figure 12. Calibration results for phytoplankton biomass (a) and zooplankton biomass (b) at site 6 .

simulation results and observed data to find an optimal value within the literature-recommended value range.

\subsection{Ecological model}

The basic principle of ecological model construction is to take biochemical processes into consideration according to the study objective, while ensuring that the model structure is not overcomplicated. Following this principle, our hypotheses for an aquatic ecological model are as follows:

1. The compartment model for each water zone is a box model, and thus all state variable concentrations and parameters in each compartment model are the same, i.e. there is no space heterogeneity.

2. In model simulations, the input concentration of each state variable at the border of two compartments is the same.
3. Baiyangdian Lake is a typical plant-dominated lake; it is necessary to reflect the changing process of aquatic plants and the influence on other ecological variables.

4. Related literature (Li, 2008; Zhang et al., 2011) considered Baiyangdian Lake to be a typical phosphoruslimited lake. In this study phosphorus was taken as the unique nutrient limiting factor influencing aquatic organisms to simplify the model structure. The state variable dissolved inorganic phosphorus (DIP) refers to orthophosphate in this study.

The ecological model of Baiyangdian Lake was constructed based on STELLA system dynamics software (ISEE Systems, Inc.; http://www.iseesystems.com/softwares/ Education/StellaSoftware.aspx). The model includes six state variables: aquatic plant biomass (AP), phytoplankton biomass (A), zooplankton biomass (Z), organic detritus (D), dissolved inorganic phosphorus in pore water (DIPP) and 
Table 4. Calibrated parameter values.

\begin{tabular}{lll}
\hline Parameters & Variation range* & Calibration results \\
\hline Eddy viscosity & $0.1-0.5\left(\mathrm{~m}^{2} \mathrm{~s}^{-1}\right)$ & 0.30 \\
Manning number & $22-32\left(\mathrm{~m}^{1 / 3} \mathrm{~s}^{-1}\right)$ & 25.00 \\
Wind friction & $0.0010-0.0015$ & 0.0013 \\
BOD processes: first-order decay rate at $20^{\circ} \mathrm{C}$ & $0-1$ (per day) & 0.25 \\
Maximum oxygen production at noon, $\mathrm{m}^{2}$ & $0-10$ (per day) & 4.00 \\
Respiration rate of plants, $\mathrm{m}^{2}$ & $0-10$ (per day) & 2.00 \\
Sediment oxygen demand per $\mathrm{m}^{2}$ & $0-10$ (per day) & 2.50 \\
Nitrification: first-order decay rate at $20^{\circ} \mathrm{C}$ & $0-1$ (per day) & 0.03 \\
Nitrification: second-order decay rate at $20^{\circ} \mathrm{C}$ & $0-2$ (per day) & 0.70 \\
Ratio of ammonium released by BOD decay & $0-2\left(\mathrm{~g} \mathrm{NH}_{4}-\mathrm{Ng} \mathrm{g}^{-1} \mathrm{BOD}\right)$ & 0.20 \\
Amount of PO 4 -P taken up by plants & $0-0.1\left(\mathrm{~g} \mathrm{P} \mathrm{g}^{-1} \mathrm{DO}\right)$ & 0.01 \\
Death rate of chlorophyll $a$ & $0-0.1$ (per day) & 0.01 \\
Settling rate of chlorophyll $a$ & $0-2$ (mday $\left.{ }^{-1}\right)$ & 0.18 \\
\hline
\end{tabular}

* Source: DHI Software Support Center (2007a, b).

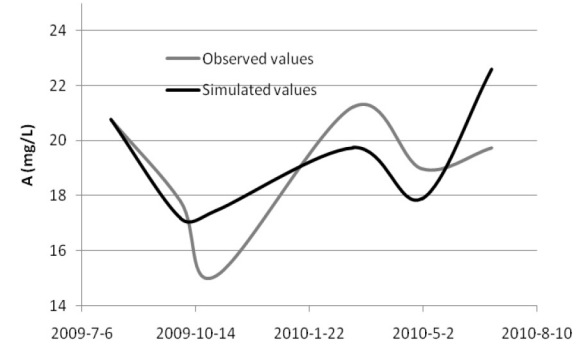

(a)

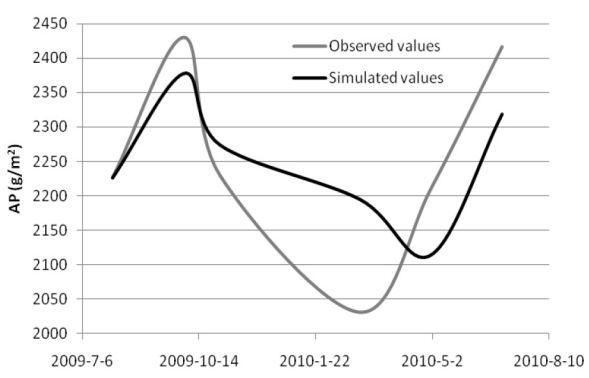

(b)

Figure 13. Calibration results for phytoplankton biomass (a) and aquatic plant biomass (b) at site 8 .

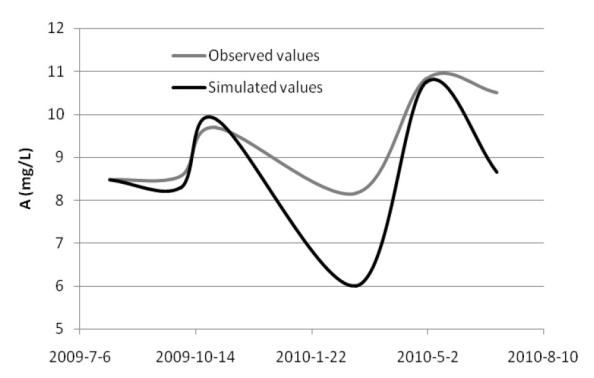

(a)

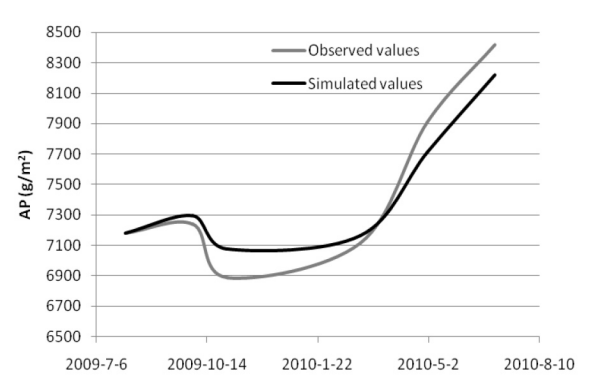

(b)

Figure 14. Calibration results for phytoplankton biomass (a) and aquatic plant biomass (b) at site 4 .

dissolved inorganic phosphorus (DIP). Conversion processes between state variables are shown in Fig. 3. Forcing functions included water level (WL), water temperature (T), solar radiation intensity (SR), river inflow, and DIP concentration of river inflow. Conversion processes for each state variable and main parameter are listed in Table 2.

\subsection{Model coupling and calibration}

In consideration of the connection between water areas, we set three movable state variables that can transfer between compartment (zone) models_-phytoplankton, organic detritus, and DIP. We did not take zooplankton into consideration because of its mobility, which may not correspond with water flow. 
Table 5. Calibrated parameter values.

\begin{tabular}{llllll}
\hline Parameter & Variation range* & $\begin{array}{l}\text { Value } \\
(\text { Zone } 1)\end{array}$ & $\begin{array}{l}\text { Value } \\
\text { (Zone } 2)\end{array}$ & $\begin{array}{l}\text { Value } \\
\text { (Zone } 3)\end{array}$ & $\begin{array}{l}\text { Value } \\
\text { (Zone 4) }\end{array}$ \\
\hline Water ratio & $0-1$ & 0.45 & 0.45 & 0.45 & 0.45 \\
CC & $5-100$ & 30 & 28 & 30 & 28 \\
DIFFC & $0.01-0.50$ & 0.12 & 0.08 & 0.10 & 0.12 \\
EXT & $0.12-0.20$ & 0.18 & 0.18 & 0.18 & 0.18 \\
GAMAX & $1-6$ & 4.30 & 5.20 & 5.70 & 4.30 \\
GPMAX & $0.02-0.50$ & 0.15 & 0.35 & 0.90 & 0.20 \\
GPOVMAX & $0.01-0.50$ & 0.07 & 0.16 & 0.41 & 0.09 \\
GZMAX & $0.30-0.80$ & 0.30 & 0.80 & 0.60 & 0.80 \\
thresh & $0.10-0.30$ & 0.20 & 0.20 & 0.20 & 0.20 \\
KA & $0.50-2.00$ & 1.00 & 0.80 & 0.60 & 1.20 \\
KP & $0.10-0.50$ & 0.30 & 0.36 & 0.40 & 0.30 \\
KPP & $0.02-0.20$ & 0.01 & 0.03 & 0.06 & 0.02 \\
Kpp1 & $0.01-0.20$ & 0.01 & 0.03 & 0.05 & 0.02 \\
KI1 & $100-500$ & 200 & 200 & 200 & 200 \\
KI2 & $100-500$ & 300 & 300 & 300 & 300 \\
MA & $0.05-0.40$ & 0.05 & 0.09 & 0.08 & 0.05 \\
MZ & $0.01-0.25$ & 0.04 & 0.05 & 0.05 & 0.06 \\
MAP & $0.005-0.10$ & 0.10 & 0.13 & 0.02 & 0.10 \\
NDC & $0.20-0.80$ & 0.20 & 0.40 & 0.40 & 0.60 \\
SDR & $0.10-2.00$ & 0.16 & 0.40 & 0.40 & 0.80 \\
SDRA & $0.10-0.60$ & 0.14 & 0.18 & 0.54 & 0.55 \\
\hline
\end{tabular}

* Source: Jørgensen and Bendoricchio (2001); Tsuno et al. (2001); Jørgensen and Fath (2011).

Table 6. Average water depth and water quality for Baiyangdian Lake.

\begin{tabular}{lcccccc}
\hline $\begin{array}{l}\text { Water } \\
\text { depth }(\mathrm{m})\end{array}$ & $\begin{array}{c}\mathrm{BOD} \\
\left(\mathrm{mg} \mathrm{L}^{-1}\right)\end{array}$ & $\begin{array}{c}\mathrm{Chl} a \\
\left(\mathrm{mg} \mathrm{L}^{-1}\right)\end{array}$ & $\begin{array}{c}\mathrm{TN} \\
\left(\mathrm{mg} \mathrm{L}^{-1}\right)\end{array}$ & $\begin{array}{c}\mathrm{TP} \\
\left(\mathrm{mg} \mathrm{L}^{-1}\right)\end{array}$ & $\begin{array}{c}\mathrm{DO} \\
\left(\mathrm{mg} \mathrm{L}^{-1}\right)\end{array}$ & $\begin{array}{c}\text { Water } \\
\text { level }(\mathrm{m})\end{array}$ \\
\hline 2.599 & 2.65 & 0.015 & 1.23 & 0.14 & 5.99 & 8.190 \\
\hline
\end{tabular}

Boundary conditions for the three movable state variables between the two compartment models were calculated as follows (DHI Software Support Center, 2007a, b; Xu et al., 2013).

For a state variable in a water area (compartment model) $n$, with inflow concentration $C_{n}$ :

$C_{n}=C_{n-1} \times F \times S_{\mathrm{cs}} / V_{n}$

$S_{\mathrm{cs}}=L \times D_{\mathrm{cs}}$

$V_{n}=A \times D$,

where $C_{n-1}$ is the concentration in water area $n-1, F$ is flow velocity at the cross section between two compartment models, $S_{\mathrm{cs}}$ is the cross-sectional area of two compartment models, $V_{n}$ is volume of water area $n, L$ is section length, $D_{\mathrm{cs}}$ is average depth at the cross section between two water areas, $A$ is water surface area and $D$ is average depth of water area $n$.

The water surface area of Baiyangdian Lake is constantly changing, so to simplify the model calculation, we first used
MIKE 21 to simulate different water levels in each compartment model and the corresponding water surface area, and then regression analysis was used to quantify the relationship between these two variables:

$V_{n}=A \times D=k \times \mathrm{WL} \times D$,

where $k$ is a regression coefficient and WL is water level.

$F, S_{\mathrm{cs}}, V_{n}, L$, and $D_{\mathrm{cs}}$ are obtained from the MIKE 21 simulation results.

Data for the six state variables obtained from field sampling carried out from August 2009 to August 2010 were used for ecological model calibration and validation. Phytoplankton and zooplankton concentrations are negligible in the inflows and were set to zero. The calibration focus was on sensitive parameters in ecological models: first, identifying a value range for each sensitive parameter from related literature; second, determining parameter values by comparison between observed values and simulated values. Two coefficients (coefficient of determination and Nash-Sutcliffe 


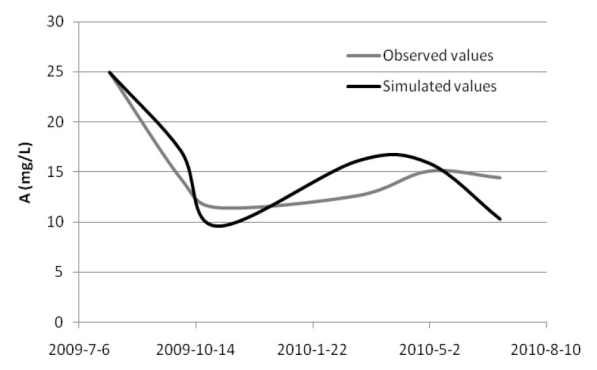

(a)

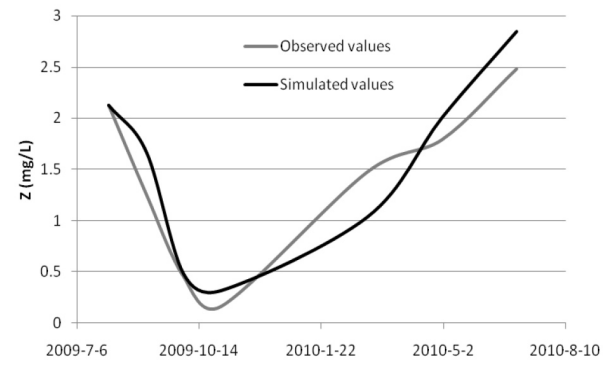

(b)

Figure 15. Calibration results for phytoplankton biomass (a) and zooplankton biomass (b) at site 12.

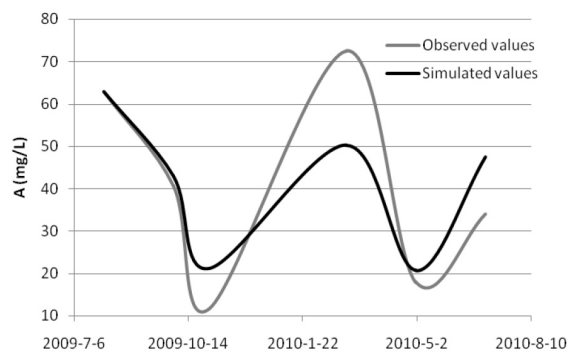

(a)

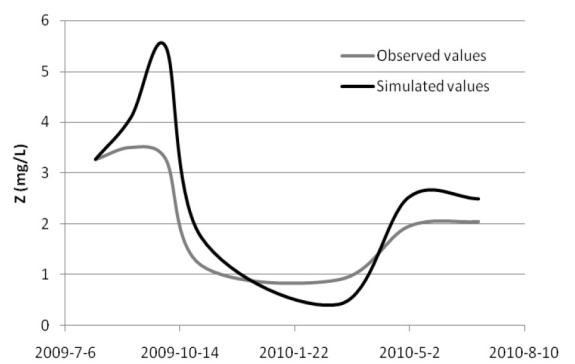

(b)

Figure 16. Validation results for phytoplankton biomass (a) and zooplankton biomass (b) at site 5.

efficiency coefficient) used for hydrodynamics and water quality model calibration and validation were also used for assessing the ecological model performance.

\section{Results and discussion}

\subsection{Water area zoning}

According to the HCA results (Fig. 4), Baiyangdian Lake was classified into five water areas when cut-off distance was 6.0: Northwest Lake (site 6 and 7), Yuanyangdao (site 5), Zaolinzhuang (site 4), Duancun (site 12), and a central water area containing the other sites (Fig. 2). According to the flow field distribution map generated by MIKE 21, five water areas reflect flow directions in Baiyangdian Lake well, which also affirmed the rationality of the HCA results. Sites 5, 6 and 7 were close to the Fu River. As the only perennial inflow to Baiyangdian Lake, the Fu River delivers high pollution loads from upstream, so these three sites were more intensely influenced by external disturbance, and had similar aquatic ecosystem features. We merged these sites into one water area to result in four compartments - zone 1 (including water areas near sites $5,6,7$ ), zone 2 (in the central water areas containing the other sites), zone 3 (water area near site 4) and zone 4 (water area near site 12).

\subsection{Sensitivity analysis}

The results of the sensitivity analysis of the effect of different parameters on the state variables are presented in Table 3. According to sensitivity classes (Lenhart et al., 2002) set for evaluating the sensitivity level of parameter $i$, the ecological model performance is most sensitive to five parameters: extinction coefficient (EXT), maximum growth rate for aquatic plant (GPOVMAX), maximum growth rate for aquatic plant (GPMAX), maximum mortality for aquatic plant (MAP), and water ratio. Moreover, these five parameters are important for all state variables, while other impactful parameters could be different.

\subsection{Calibration and validation results}

\subsubsection{Hydrodynamics and water quality model}

Calibration results are shown in Table 4, and the other parameters used model-recommended values. Judging from the comparison between observed and simulated values (Figs. 511), good simulation results were achieved, indicating that the model can accurately reflect water levels and water quality in Baiyangdian Lake.

\subsubsection{Ecological model}

Four typical monitoring points were selected for model calibration - site 6 (zone 1), site 8 (zone 2), site 4 (zone 3), and 


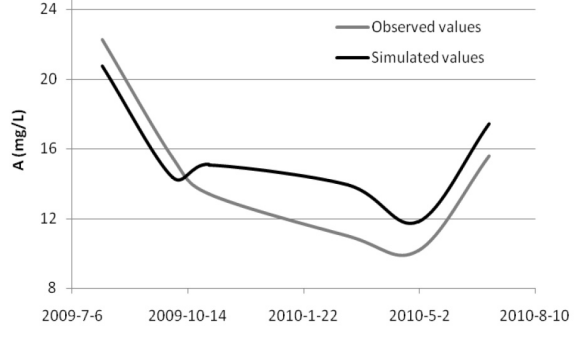

(a)

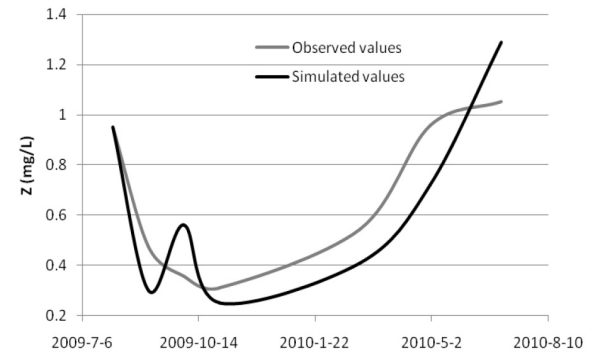

(b)

Figure 17. Validation results for phytoplankton biomass (a) and zooplankton biomass (b) at site 10 .
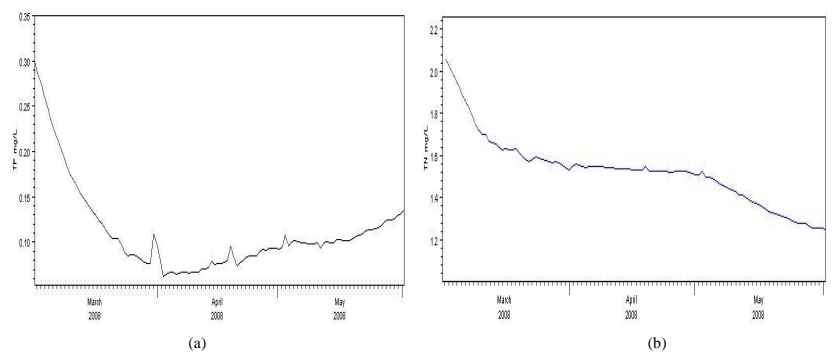

Figure 18. Changes in concentrations of $\mathrm{TP}(\mathbf{a})$ and $\mathrm{TN}(\mathbf{b})$ at site 8.

site 12 (zone 4) (Figs. 12-15). Calibration results are shown in Table 5. Because only one year of data was available, we selected two monitoring points - site 5 (zone 1) and site 10 (zone 2) - for model validation. Spatially sampled data are substituted for time series data to overcome the limitations of the available time series data. Judging from the comparison between observed and simulated values (Figs. 16 and 17), good simulation results were achieved, indicating that the ecological model can reasonably reflect changes in ecological state variables in the study area.

\subsection{Model performance}

In the hydrodynamics and water quality model calibration period, simulation effects for BOD, DO, and phosphate were more accurate than for $\mathrm{TN}$ when comparing simulations and observed values. This could be because TN concentration from upstream inflow or non-point source discharge is stochastic with high uncertainty. The observed values were influenced by anthropogenic factors or extreme weather events, thus resulting in large differences between observed and simulated values. In the model validation period, simulation effects for TN showed further improvement, indicating that the model has good portability and reusability. Taken together, we conclude that parameter setting was appropriate and the hydrodynamics and water quality model can accurately reflect changes in water level and quality in the study area.

As can be seen from Figs. 12 to 15, the ecological model can accurately reflect changes in ecological state variables for each water area, though there are some discrepancies in peak fitting during the model calibration and validation period. This is not surprising given the complexity of interactions affecting species succession and bloom, and considering that spatial processes in each water area zone are averaged in this modelling approach. In contrast to system dynamic modelling, a weakness of the structured model is that biological groups and characteristics are not assigned a high priority by the users (Jørgensen, 1999). The low frequency of measurements is also a possible explanation for this phenomenon. We can also see from Table 7 that the sample fitting effect in zone 1 was the worst for the four water area zones during the model calibration period. The main reasons are that zone 1 is near the Fu River, which introduces wastewater inflow from upstream, and tourism is also popular in this area. These two factors lead to high concentrations of nitrogen and phosphorus and result in low simulation precision for zone 1. Simulation results further illustrate the necessity of considering spatial variations when simulating ecological changes. The compartmental ecological model we constructed takes the connection between water areas into consideration and provides a new method for simulating water ecological changes accurately and comprehensively.

Our hydrodynamics and water quality model and compartmental ecological model are shown to be conceptually straightforward and computationally efficient tools for lake prediction and management. It is important to note that no single model for water quality or aquatic ecology is suitable for all applications. The two models we established are part of a larger set of models designed to help guide management decision-making processes. We suggest that the compartmental ecological model could be of value in understanding and testing alternative scenarios for management of other similar middle-scale or large-scale lake ecosystems. For a damaged system such as that of Baiyangdian Lake, in which a series of wetland ecosystem restoration measures including watershed pollution load control and ecological water transfer were carried out, modelling efforts that link hydrodynamics, water quality, and aquatic ecology provide needed management decision-making support. 


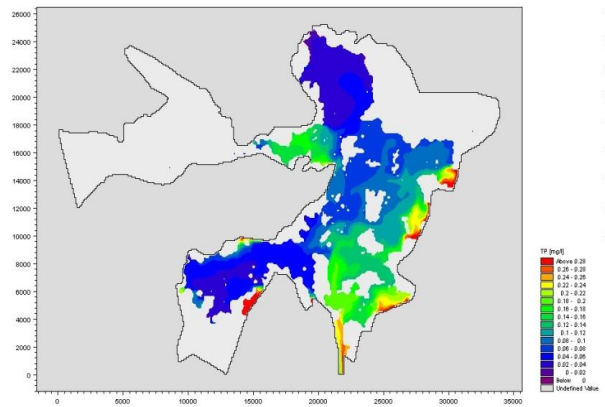

(a)

Figure 19. Spatial variations in concentrations of TP (a) and TN (b).
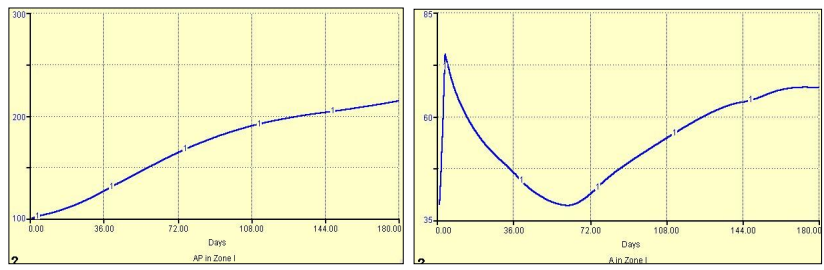

Figure 20. Simulation results for the main ecological indices for zone 1. (a) Aquatic plant biomass (AP); (b) phytoplankton biomass (A).
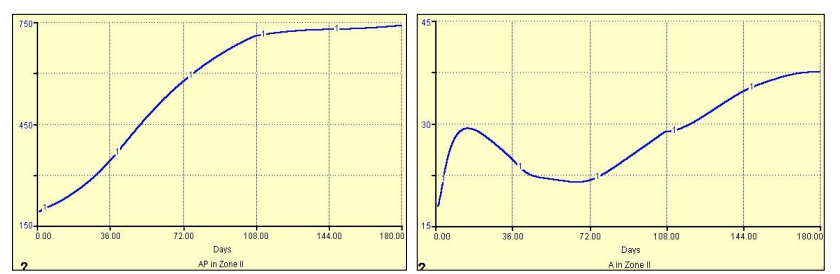

Figure 21. Simulation results for the main ecological indices for zone 2. (a) Aquatic plant biomass (AP); (b) phytoplankton biomass (A).

\subsection{Application of coupled lake models for predicting ecological conditions}

The coupled lake model was applied to simulate spatial variations in ecological conditions to reflect the application effect of water supplementation in lake restoration and management. The scenario was set as follows.

In a normal year (the runoff from the Fu and Xiaoyi rivers is equal to the mean annual river runoff) two water diversion projects, the Yellow River-to-Baiyangdian Lake diversion and diversion from upstream reservoirs are implemented. The water volume of the former project is 100 million $\mathrm{m}^{3}$, and water quality meets China Environmental Quality Standards for Surface Water Class. The water volume of the latter project is 60 million $\mathrm{m}^{3}$, and water quality meets Class IV of the Standards.

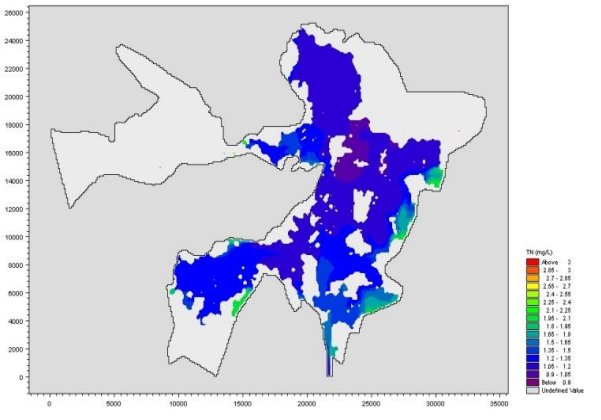

(b)
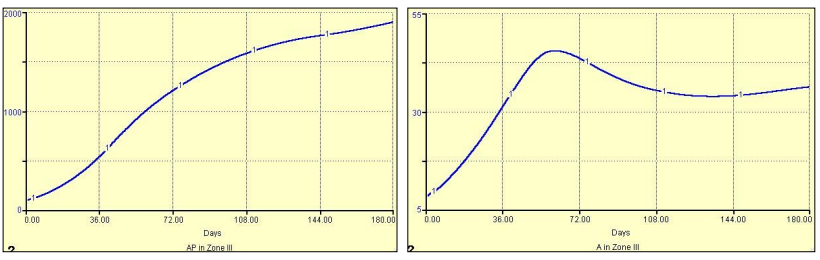

Figure 22. Simulation results of the main ecological indices for zone 3. (a) Aquatic plant biomass (AP); (b) phytoplankton biomass (A).
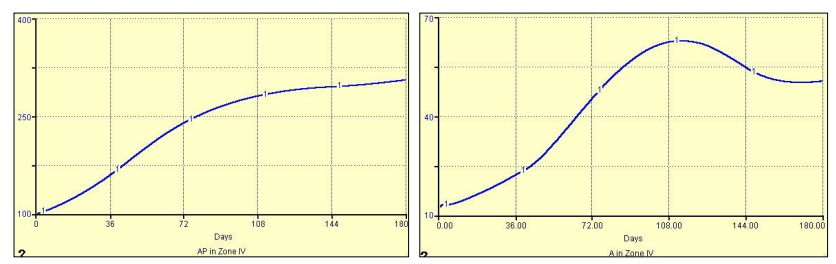

Figure 23. Simulation results of the main ecological indices for zone 4. (a) Aquatic plant biomass (AP); (b) phytoplankton biomass (A).

Initial conditions and boundary conditions for the scenario were input in the MIKE 21 model for the hydrodynamic and water quality simulation. Simulation results are shown in Tables 6 and 7.

Changes in TN and TP concentrations at site 8 are shown in Fig. 18. Spatial variations in TN and TP concentrations across Baiyangdian Lake are shown in Fig. 19. The simulation results (Fig. 18) for TP and TN concentrations showed an apparent decrease after water supplementation. The final values for TP and TN concentrations were 0.13 and $1.25 \mathrm{mg} \mathrm{L}^{-1}$, which decreased by 68.1 and $82.4 \%$, respectively, and which meet Standards Class.

The hydrodynamic simulation results were input to the water ecological model as hydrodynamic boundary conditions between two compartments for aquatic ecological simulation. Simulation results are shown in Table 8. Simulation 
Table 7. Average water depth and water quality for different water area zones.

\begin{tabular}{lcccccc}
\hline Zone & $\begin{array}{c}\text { Water } \\
\text { depth }(\mathrm{m})\end{array}$ & $\begin{array}{c}\mathrm{DO} \\
\left(\mathrm{mg} \mathrm{L}^{-1}\right)\end{array}$ & $\begin{array}{c}\mathrm{Chl} a \\
\left(\mathrm{mg} \mathrm{L}^{-1}\right)\end{array}$ & $\begin{array}{c}\text { BOD } \\
\left(\mathrm{mg} \mathrm{L}^{-1}\right)\end{array}$ & $\begin{array}{c}\mathrm{TN} \\
\left(\mathrm{mg} \mathrm{L}^{-1}\right)\end{array}$ & $\begin{array}{c}\mathrm{TP} \\
\left(\mathrm{mg} \mathrm{L}^{-1}\right)\end{array}$ \\
\hline I & 1.97 & 6.00 & 0.122 & 2.33 & 3.30 & 0.18 \\
II & 2.71 & 6.02 & 0.019 & 3.09 & 0.93 & 0.14 \\
III & 3.39 & 5.21 & 0.018 & 4.29 & 1.68 & 0.18 \\
IV & 2.64 & 6.12 & 0.017 & 3.39 & 0.69 & 0.11 \\
\hline
\end{tabular}

Table 8. Water ecological indices of different water area zones.

\begin{tabular}{lccrr}
\hline Zone & $\begin{array}{c}\mathrm{Z} \\
\left(\mathrm{mg} \mathrm{L}^{-1}\right)\end{array}$ & $\begin{array}{c}\mathrm{A} \\
\left(\mathrm{mg} \mathrm{L}^{-1}\right)\end{array}$ & $\begin{array}{r}\mathrm{D} \\
\left(\mathrm{mg} \mathrm{L}^{-1}\right)\end{array}$ & $\begin{array}{r}\mathrm{AP} \\
\left(\mathrm{g} \mathrm{m}^{-2}\right)\end{array}$ \\
\hline 1 & 4.29 & 66.95 & 11.29 & 214.58 \\
2 & 4.34 & 37.57 & 10.94 & 742.37 \\
3 & 4.75 & 36.33 & 7.34 & 1903.18 \\
4 & 2.81 & 50.78 & 8.41 & 345.21 \\
\hline
\end{tabular}

results of the key aquatic ecological indices for the four water area zones are shown in Figs. 20-23.

\section{Conclusions}

In view of the interplay between water quality and aquatic ecology, a coupled lake model with a hydrodynamics and water quality model established by MIKE 21 and a compartmental ecological model using STELLA software has been established for Baiyangdian Lake to simulate spatial variations in ecological conditions. On the basis of the flow field distribution results generated by the MIKE 21 hydrodynamics model, four water area zones were used for compartmental ecological model calibration and validation. The results revealed that the coupled lake model can reasonably reflect changes in key state variables, although there remain some state variables that are not well represented by the model due to the low quality of field monitoring data. Monitoring sites in a compartment may not be representative of the water quality and ecological conditions in the entire compartment even though that is the intention of compartment-based model design. There was only one ecological observation from a single monitoring site for some periods. This singlemeasurement issue may cause large discrepancies, particularly when the sampled site is not representative of the whole compartment. Therefore, increasing sampling sites and frequency might improve the model's statistical performance.

The coupled model was used to simulate spatial variations in ecological conditions under water supplementation to reflect the supplementation effects in lake restoration and management. The simulation results indicate that the model is a useful tool. The simulated spatial variation trends are a foundation for establishing permissible ranges for a selected set of water quality indices, as part of management measures such as watershed pollution load control and ecological water transfer. Meanwhile, the coupled model increases understanding of processes and interactions between components in the lake ecosystem and external conditions.

Taken together, the proposed models we established show promising applications as meso-scale or large-scale lake management tools for pollution load control and ecological water transfer. These tools quantify the implications of proposed future water management decisions. Future research should focus on scenario setting, simulation, and evaluation of different management measures.

Acknowledgements. Special thanks to the National Natural Science Foundation of China (grant no. 51279009), the International Science \& Technology Cooperation Programme of China (no. 2011DFA72420), and the National Basic Research Programme of China (no. 2013CB430402) for financial support.

Edited by: Y. Cai

\section{References}

Cai, Y. P., Huang, G. H. Tan, Q., and Chen, B.: Identification of optimal strategies for improving eco-resilience to floods in ecologically vulnerable regions of a wetland, Ecol. Model., 222, 360369, 2011.

Ciric, C., Ciffroy, P., and Charles, S.: Use of sensitivity analysis to identify influential and non-influential parameters within an aquatic ecosystem model, Ecol. Model., 246, 119-130, 2012.

Cox, B. A.: A review of currently available in-stream water-quality models and their applicability for simulating dissolved oxygen in lowland rivers, Sci. Total Environ., 314, 335-377, 2003.

DHI Software Support Center: MIKE 21 ECO Lab, Scientific Description. MIKE Zero Products, DHI Water \& Environment, Hørsholm, Danmark, 2007a.

DHI Software Support Center: MIKE 21 ECO Lab, User Guide, MIKE Zero Products, DHI Water \& Environment, Hørsholm, Danmark, 2007b.

Gal, G., Hipsey, M. R., Parparov, A., Wagner, U., Makler, V., and Zohary, T.: Implementation of ecological modeling as an effective management and investigation tool: Lake Kinneret as a case study, Ecol. Model., 220, 1697-1718, 2009. 
He, G. J., Fang, H. W., Bai, S., Liu, X. B., Chen, M. H., and Bai, J.: Application of a three-dimensional eutrophication model for the Beijing Guanting Reservoir, China, Ecol. Model., 222, 1491$1501,2011$.

Jørgensen, S. E.: State-of-the-art of ecological modelling with emphasis on development of structural dynamic models, Ecol. Model., 120, 75-96, 1999.

Jørgensen, S. E.: A review of recent developments in lake modelling, Ecol. Model., 211, 689-692, 2010.

Jørgensen, S. E. and Bendoricchio, G.: Fundamentals of ecological modelling, 3rd Edn., Elsevier, UK, 2001.

Jørgensen, S. E. and Fath, B. D.: Fundamentals of ecological modelling, 4th Edn., Elsevier, UK, 2011.

Kingsford, R. T.: Conservation management of rivers and wetlands under climate change-a synthesis, Mar. Freshwater Res., 62, 217-222, 2011.

Lenhart, T., Eckhardt, K., Fohrer, N., and Frede, H. G.: Comparison of two different approaches of sensitivity analysis, Phys. Chem. Earth, 27, 645-654, 2002.

Li, J. W.: Study on water environment quality and ecoenvironmental water requirement of Baiyangdian, M.S. thesis, Hebei Agricultural University, China, 2008.

Martins, G., Ribeiro, D. C., Pacheco, D., Cruz, J. V., Cunha, R., Gonçalves, V., Nogueir, R., and Brito, A. G.: Prospective scenarios for water quality and ecological status in Lake Sete Cidades (Portugal): The integration of mathematical modelling in decision processes, Appl. Geochem., 23, 2171-2181, 2008.
Miller, C. T., Dawson, C. N., Farthing, M. W., Hou, T. Y., Huang J. F., Kees, C. E., Kelley, C. T., and Langtangen, H. P.: Numerical simulation of water resources problems: Models, methods, and trends, Adv. Water Resour., 51, 405-437, 2013.

Missaghi, S. and Hondzo, M.: Evaluation and application of a threedimensional water quality model in a shallow lake with complex morphometry, Ecol. Model., 221, 1512-1525, 2010.

Muhammetoğlu, A. B. and Soyupak, S.: A three-dimensional water quality-macrophyte interaction model for shallow lakes, Ecol. Model., 133, 161-180, 2000.

Rubec, C. D. A. and Hanson, A. R.: Wetland mitigation and compensation: Canadian experience, Wetlands Ecol. Manage., 17, 3 14, 2009.

Tsuno, H., Hidaka, T., and Jørgensen, S. E.: Scientific description for the PAMOLARE training package, CP/DK, UNEP-DTIEIETC and ILEC, Japan, 2001.

Wang, H. Q., Meselhe, E. A., Waldon, M. G., Harwell, M. C., and Chen, C. F.: Compartment-based hydrodynamics and water quality modeling of a Northern Everglades Wetland, Florida, USA, Ecol. Model., 247, 273-285, 2012.

Wang, N. M. and Mitsch, W. J.: A detailed ecosystem model of phosphorus dynamics in created riparian wetlands, Ecol. Model., 126, 101-130, 2000.

Xu, F., Yang, Z. F., Chen, B., and Zhao, Y. W.: Development of a structurally dynamic model for ecosystem health prognosis of Baiyangdian Lake, China, Ecol. Indic., 29, 398-410, 2013.

Zhang, J. R., Zeng, Y., and Zhao, Y. W.: Threshold analysis of water blooms in Baiyangdian wetlands, Chin. J. Ecol., 30, 1744-1750, 2011. 